\title{
ИННОВАЦИОННАЯ АКТИВНОСТЬ
}

\author{
А. А. Максимов, А. В. Молодчик, Т. А. Максимов
}

\section{ПРОБЛЕМЫ ИНТЕГРАЦИИ ИННОВАЦИОННЫХ ПРЕДПРИЯТИЙ И ИССЛЕДОВАТЕЛЬСКОГО УНИВЕРСИТЕТА}

\begin{abstract}
В статье рассматриваются вопросы инноваиионного развития экономики посредством интеграции университетов с инновационными компаниями. На примере $3 А О$ «Пермская компания нефтяного машиностроения» и Пермского государственного технического университета рассматриваются проблемы развития предприятий, вузовской науки и возможность их решения путем создания инновационных кластеров и научно-исследовательских центров. В статье также приводится организационная схема создания НИЦ, организационная структура управления ими и описаны инструменты инновационного развития с точки зрения системного подхода.
\end{abstract}

Инновационное развитие по определению предполагает взаимодополняющее единство процессов создания и коммерциализации инноваций. В общем случае именно коммерциализация инноваций формирует источники развития. Коммерциализация инновационной деятельности есть трансформация инноваций в реальный бизнес и его доведение до стадии получения дохода в объеме, превышающем совокупные затраты всех стадий инновационного процесса.

Процесс коммерциализации инвестиционной деятельности является специфическим видом деятельности и реализуется в различных формах, которые объединяет одно - инновационный продукт должен быть востребован рынком. Мировой опыт показывает опережающее развитие модели открытых инноваций, в рамках которой компании коммерциализируют не только внутренние, но главным образом, внешние идеи, используя возможности инновационной деятельности вне своего текушего бизнеса $[1,2]$. Отличительной чертой открытой инновационной модели является возможность отбора идей, что в конечном итоге повышает вероятность успеха последующей коммерци- ализации. Эффективной формой реализации открытой модели являются инновационные кластеры, предполагающие сотрудничество субъектов инновационного процесса, активное развитие форм интеграции.

В государственном концепте формирования инновационной экономики к потенциально эффективным субъектам инновационной деятельности отнесены высшие учебные заведения, среди которых ведущая роль отводится университетам, в отношении которых устанавливается категория «национальный исследовательский университет» (НИУ). Постановлением Правительства РФ от 13 июля №550 определены требования к структуре и содержанию программ развития национальных университетов, из которых следует их роль как центров создаваемых на базе НИУ инновационных кластеров, генераторов развития технологической, информационной, консалтинговой, образовательной и финансовой инфраструктуры инновационной деятельности. В силу этого развитие кооперационных связей между субъектами инновационных процессов становится одним из ключевых направлений деятельности НИУ. При этом ведушее место в системе кооперационных связей инновационных кластеров занимают партнерства НИУ и инновационных компаний, формирующие основу инновационного развития и коммерциализации инноваций. С практической точки зрения вопрос построения моделей взаимодействия НИУ и инвестиционных компаний был и продолжает оставаться наиболее актуальным.

По-прежнему эффективным остается традиционный подход, когда компании в осуществлении инвестиционной деятельности опираются на научно-технический потенциал вузов, выступая заказчиками-постановщиками задач и инвесторами в одном лице. В этом случае стра- 
тегическое партнерство предопределяет постоянную нацеленность вузовских специалистов на решение перспективных задач, сотрудничество позволяет идти в ногу со временем, обеспечивая доступ к новым технологиям и ускоряя инновационный процесс. Во многих странах такое партнерство также плодотворно развивается, поскольку вузы при достаточно высоком качестве предоставляют научно-исследовательские услуги и мощности по гораздо более низким ценам, чем коммерческие исследовательские организации. Нередко результатом исследований, выполненных в вузе, является и появление нового бизнеса в какой-либо форме партнерства. В современной России практика финансирования исследовательских работ, выполняемых силами высшей школы по заказам инвестиционных компаний, в значительной степени сократилась. Сотрудничество развивается главным образом в вариантах взаимодействия учебных заведений и крупных вертикально интегрированных компаний, в частности, нефтяных.

Следует, к сожалению, констатировать, что значительное число потенциально инновационных предприятий, нацеленных на сотрудничество с высшей школой, в настоящих условиях финансово не готовы к такой кооперации. Общей проблемой динамично развивающих инновации компаний был и продолжает оставаться недостаток ресурсов для осуществления НИОКР. В текущий момент ситуация усугубляется проявлением системных кризисных явлений российской экономики, которые находят проявления в различных формах и сферах. Это и нежелание банков кредитовать реальный сектор при избытке ликвидности, и сохранение непозволительно высокой эффективной ставки кредитования, и колоссальное коррупционное давление бюрократической системы, использующей изъяны институциональной среды в войне против бизнеса, и приступы обострения «голландской болезни», и многое другое [1]. Монополизация практически всех сырьевых и околосырьевых отраслей - основных источников российских финансов - вкупе с отсутствием внятной деполитизированной позиции антимонопольных органов, позволяет основным игрокам диктовать любые, нередко на грани фола, условия взаимодействия с сервисными компаниям и компаниями-производителями оборудования (а ведь именно в этих компаниях остался на сегодня основной инновационный потенциал). Например, с ноября 2008 г. все вертикально интегрированные нефтяные компании в одностороннем порядке увеличили период отсрочки платежа за поставленную продукцию и произведенные услуги с 30 до 90 дней. В этих условиях даже при относительно высокой эффективности производства, практически все заработанные средства - источник финансирования НИОКР, направляются на пополнение оборотных активов. В то же самое время в инновационных портфелях компаний продолжают накапливаться нереализованные, практически значимые проекты, отсутствие которых все острее ощущается в науке, в частности в науке высшей школы.

При этом Правительство РФ продолжает рассматривать исследования, проводимые в сфере высшего образования, как значительный потенциал активизации инновационной деятельности, как катализатор процесса формирования инновационных систем, инструмент перераспределения ресурсной ренты. Можно предположить, что именно с учетом реалий сегодняшнего дня научно-исследовательские университеты определены как центры, образующие инновационные кластеры, наделенные значительными финансовыми ресурсами, что в результате формирует основу построения новых схем интеграции бизнеса и высшей школы.

В частности, практически реализуемым вариантом инновационного развития может стать такая интеграционная модель, в которой инновационные предприятия выступают в качестве постановщиков задач, координаторов и участников процессов исследований. В отдельных случаях выполняют функции соинвесторов. Тогда как исследовательские университеты берут на себя роль основных инвесторов и ведущих исполнителей. Участниками проектов могут быть крупные интегрированные компании - потребители продукции предприятий среднего бизнеса и, по сути, реальные бенефициары инновационных процессов (рис. 1).

Такая постановка является вполне жизнеспособной при условии четких ответов на два вопроса:

- каким структурно будет финансирование инновационного процесса с позиций затрат;

- как будут решаться вопросы правообладания на создаваемый в рамках партнерства интеллектуальный продукт?

Исходя из заданных государством условий расходования выделенных исследовательским университетам средств, основными направлениями инвестиций со стороны высшей школы должны быть вложения в оборудование для 


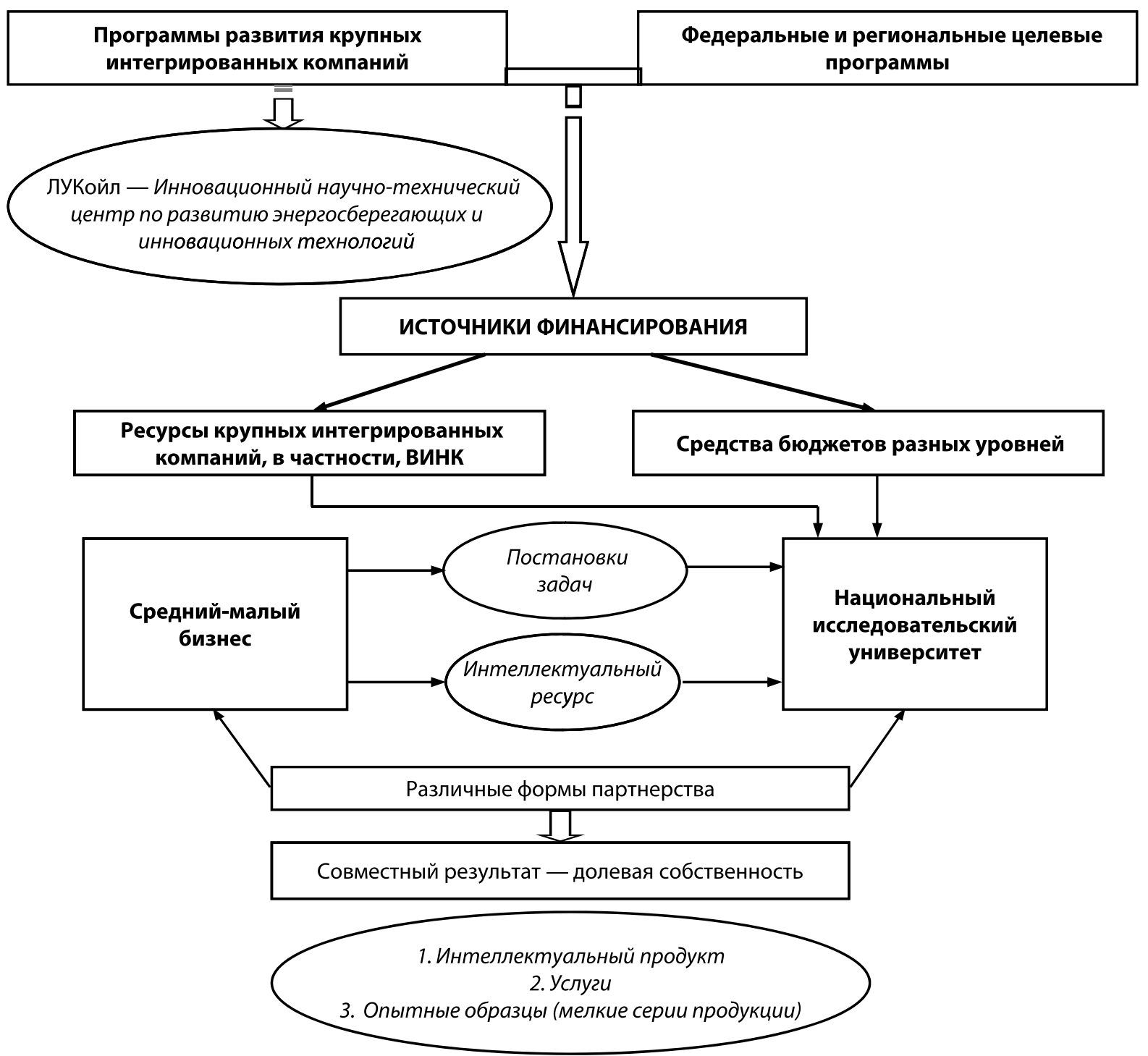

Рис. 1. Схема интеграции НИУ с инновационным бизнесом

проведения исследований. Отбор оборудования, нашему мнению, целесообразно производить таким образом, чтобы его можно было использовать не только как лабораторную базу, но и для оказания услуг по профилю исследований и для производства опытных образцов мелкими сериями. В такой постановке вопросы текущего финансирования исследований могут закрываться из следующих основных источников:

- ресурсов инвестиционной компании участника проекта;

- ресурсов крупных интегрированных компаний - участников проекта;

- ресурсов, зарабатываемых за счет оказания профильных услуг и реализации опытных образцов;

- ресурсов бюджетов различных уровней в формах целевого финансирования, грантов, оплаты творческих отпусков и пр.
Создаваемая в рамках партнерства интеллектуальная собственность в общем случае должна быть долевой. Размер долей является предметом договоренностей в каждом конкретном случае.

Практическую реализацию рассмотренного подхода представляет проект создания Международного центра разработок, исследований, метрологии и надежности резьбовых соединений (МЦРС), прорабатываемый в настоящее время национальным исследовательским университетом - ПГТУ (НИУ-ПГТУ) со специалистами Пермской компании нефтяного машиностроения (ПКНМ).

ЗАО «Пермская компания нефтяного машиностроения» - один из крупнейших производителей нефтепромыслового (НПО) и бурового оборудования в России. Компания производит:

- штанговые скважинные насосы (СШН) широкой номенклатуры, дополнительные уст- 
ройства (замковые опоры, автосцепы, газосепараторы, шламоуловители и др.), запчасти к ним, производится полное сервисное обслуживание и ремонт;

- утяжеленные (УБТ), ведущие (ВБТ) и толстостенные (ТБТ) бурильные трубы в соответствии с API Spec 7-1.

- насосно-компрессорные трубы, высокоточные и коррозиестойкие трубы для корпусов ПЭН, ПЭД, корпусы и гильзы газосепараторов, диспергаторов и гидрозащиты, передельные трубы из хромоникелевых и немагнитных сплавов.

Продукция компании сертифицирована по международным стандартам качества ISO и API. ЗАО ПКНМ имеет право на простановку официальной монограммы API на скважинные штанговые насосы СШН (лицензия № 11AX0077 от 24.09.2007), ведущие трубы ВБТ и утяжеленные трубы УБТ (лицензия № 7-1-0594 от 24.09.2007).

В области резьбовых соединений для нефтяной и газовой промышленности специалисты компании без преувеличения входят в техническую элиту российского машиностроения.

Национальный исследовательский университет - ПГТУ создан на базе Пермского государственного технического университета, который в конкурсе вузов России 2009 г. на присвоение статуса «Национальный исследовательский университет» стал одним из 12 вузов-победителей. Министерством образования и науки РФ утверждена программа развития на 20092018 гг., в которой зафиксированы следующие приоритетные направления развития (ПНР):

- авиационное двигателестроение и газотурбинные технологии;

- добыча и переработка нефти, газа и полезных ископаемых;

- наноиндустрия;

- урбанистика.

МЦРС создается в рамках ПНР «Добыча и переработка нефти, газа и полезных ископаемых». Структурно центр состоит из трех секторов:

1. Сектор исследований эксплуатационных характеристик и разработок новых резьбовых соединений (РС):

- исследование прочности, усталостной прочности, износостойкости, коррозионной стойкости, герметичности РС;

- разработка новых оптимальных РС.

2. Сектор технологий формирования и упрочнения $\mathrm{PC}$ :
- разработка технологий формирования PC, способов упрочнения: пластической деформацией, химико-термической обработкой, покрытиями;

- разработка оборудования, инструментов оснастки;

- разработка методов контроля.

3. Сектор метрологии, надежности, сертификации:

- измерения параметров РС;

- аттестация средств измерений (калибров), в том числе по ISO и API;

- исследования (экспертиза) разрушения резьбовых соединений;

- разработка ТУ, стандартов.

Выбранная структура МЦРС является интегрированным результатом морфологического анализа основных направлений исследований, стратегических направлений развития ПКНМ и маркетинговых исследований потенциальных рынков [3].

Принципиально важным моментом, определяющим практическую реализуемость проекта, является объем доли рынка услуг, на которую может потенциально претендовать МЦРС. По оценке специалистов ПКНМ, уже на первых этапах деятельности МЦРС может объемные показатели, приведенные в таблице.

Указанный объем услуг может быть реализован центром только при условии его аттестации (заявочным порядком) Американским нефтя-

\begin{tabular}{|c|c|c|c|c|}
\hline \multirow[b]{2}{*}{$\begin{array}{l}\text { Направления } \\
\text { деятельности }\end{array}$} & \multicolumn{4}{|c|}{ Потребители продукции, услуг } \\
\hline & 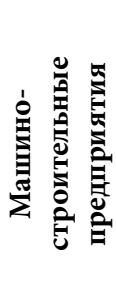 & 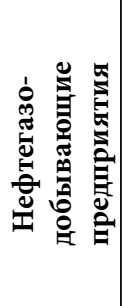 & 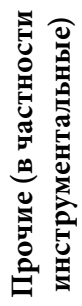 & 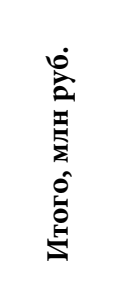 \\
\hline $\begin{array}{l}\text { Сертификация и } \\
\text { поверка и мастер-ка- } \\
\text { либров, в том числе } \\
\text { по ISO и API (калиб- } \\
\text { ров в год) }\end{array}$ & 2500 & 1000 & 500 & $120-160$ \\
\hline $\begin{array}{l}\text { Проведение исследо- } \\
\text { ваний качества резь- } \\
\text { бовых соединений } \\
\text { при периодических } \\
\text { испытаниях и ава- } \\
\text { рийных ситуациях } \\
\text { (заявок в год) }\end{array}$ & 50 & 200 & 50 & $3-5$ \\
\hline $\begin{array}{l}\text { Предоставление ин- } \\
\text { формационных услуг }\end{array}$ & & & & $2-3$ \\
\hline
\end{tabular}


ным институтом (American Petroleum Institute API). При этом учитывается, что специалисты ПКНМ имеют значительный опыт сертификации своей продукции по стандартам API. В настоящее время ведется работа по уточнению требований API к подобным центрам (ближайшие расположены в Англии и Китае). На текущей стадии проработки проекта объем минимально необходимых затрат на приобретение оборудования составляет порядка 240 млн руб. В состав производственно-исследовательской базы центра планируется включить технологическое оборудование, контрольно-измерительную машину для контроля геометрических параметров резьбы образцов и калибров, металлографический микроскоп для исследования физико-механических показателей качества поверхностного слоя резьб, оборудование для определения твердости (Бринелль, Роквелл, Виккерс, микротвердость), оборудование для механических испытаний (на растяжение, сжатие, изгиб, кручение, на ударную вязкость, испытания на сопротивление разрыву трещин, испытания в сложнонагруженном состоянии), стенды для исследования ползучести, длительной прочности, трибологических характеристик, усталости, многоцикловой усталости резьбовых пар, имитирующие условия работы резьбовых соединений при монтаже и эксплуатации на натурных образцах, либо моделях, стенды для гидроиспытаний, включающие потенциальное оборудование (компрессоры или баллоны для создания рабочих давлений), оборудование для неразрушающего контроля (рентгеновская, ультразвуковая, магнитная, капиллярная, акустоэмиссионная дефектоскопии), оборудование для контроля химического состава (химический метод, спектральный и рентгеноспектральный анализы), оборудование для контроля специальных свойств (магнитной проницаемости, межкристаллитной коррозии, обезуглероженного слоя), калибры-эталоны и мастер-калибры.

Затраты на приобретение информации об имеющихся резьбовых соединениях:

- ГОСТ 631-75, 632-80, 633-80, 7909-56, 7918-56, 7918-75, 6111-52, 9150-81, P50684-96, 6357-73, P51161-2002, 9484-81, 24737-81;

- OCT 39-226-91;

- ТУ 1324-010-26602587-2007, 0071-00220970456-2010,

- API спец. 7-2,5B, 11AX, 11B-NC, REG, FH, CSG, LCSG, BCSG, XCSG, LP, TBG, UPTBG;
- ASME/AHSI B1.8-1988;

- VALLOUREC-VAM,NEW-VAM);

a также на получение разрешающих документов на применение, контроль и сертификацию лаборатории по аттестации калибров составляют - 50 млн руб.

Для создания центра требуются площади порядка $500 \mathrm{~m}^{2}$.

Принципиально важным является то, что за последние три года университетом приобретено уникальное научное оборудование и прикладное программное обеспечение, расширен доступ к информационным ресурсам, при поддержке НК ЛУКойл создан Институт нефти и газа. Поэтому значительная часть необходимого для создания МЦРС оборудования уже имеется в наличии, хотя и распределена по различным факультетам и кафедрам.

Из представленной на рис. 2 принципиальной организационной схемы создания МЦСР видно, что реализация проекта предполагает два этапа. На первом этапе создается лаборатория резьбовых соединений в структуре НИУ-ПГТУ, которая является базой для проведения работ в рамках центра. Далее на основе объединения специалистов ПКНМ и НИУ осуществляется комплекс мероприятий по развитию МЦСР. По предварительной оценке окупаемость проекта после завершения сертификации центра при $25 \%$-ной рентабельности работ составит не более 4-5 лет. При этом жизненный цикл проекта представляется достаточно длинным, даже исходя из ограниченного перечня рассмотренных выше поставленных перед центром задач.

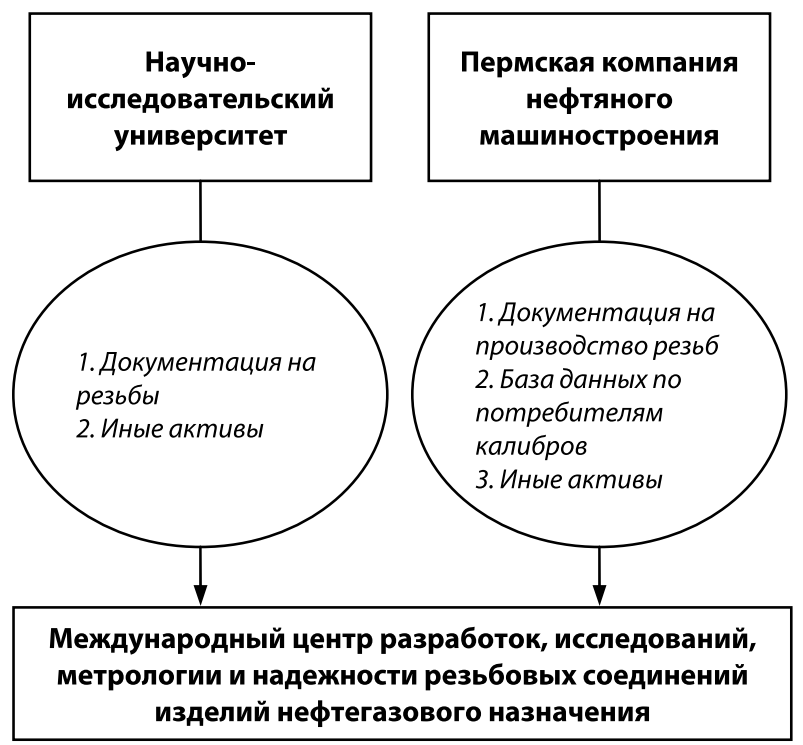

Рис. 2. Принципиальная организационная схема создания МЦРС 
Вместе с тем реализация проекта МЦСР, несмотря на хорошие перспективы и приемлемые показатели эффективности, остается достаточно проблематичной в связи с неразрешенностью многих вопросов, в первую очередь финансово-организационных.

В частности, остается открытым вопрос финансирования работ по открытию лаборатории резьбовых соединений в структуре НИУ-ПГТУ, организации и сертификации самого МЦРС. Практика взаимодействия с API показывает, что данный процесс может занять от 3 до 5 лет, притом что активная фаза зарабатывания денег в МЦРС должна начаться после прохождения сертификационных процедур. Жесткие условия расходования выделенных ПНИУ средств не позволяют напрямую использовать их для этих целей. Кроме того, нет четких требований к срокам реализации и окупаемости проектов. В идеале желательно деньги потратить одномоментно и на следующий день начинать получать прибыль.

ПКНМ в настоящее время и в обозримом будущем все ресурсы вынуждена направлять на пополнения оборотных средств. При этом тенденция их вымывания набирает силу в связи с изменением сроков платежей со стороны нефтяных компаний, несоблюдением платежной дисциплины в условиях рецессии, инфляционной составляющей, неритмичностью работы производителей трубной заготовки и т. п. Достаточно отметить, что за 2009 г. кредиторская и дебиторская задолженности удвоились, оставаясь паритетными.

Вопросы участия в проекте вертикально интегрированных нефтяных компаний (ВИНК) находятся в стадии постановки и требуют проработки принципиальных решений.

Не менее актуальным является вопрос завоевания доли на рынке услуг, на выполнение которых ориентируется МЦСР. Традиционно сильной остается ориентация крупных компаний, особенно нефтяных, на взаимодействие с иностранными центрами и консультантами. В процессе предварительного обсуждения идеи центра с представителями ведущей российской нефтяной компании был получен положительный отзыв, ценность которого тут же перечеркнул вопрос в развитие темы: «А чем нам плохо работать с Лондоном?»

Проблемными представляются и вопросы взаимодействия с государственными структурами - надзорными, судебными, аттестационными.
Кадровая тема была и остается актуальной. Особенно острой она становится в сложных инновационных проектах, предполагающих единство науки, фундаментальной и прикладной, опытно-конструкторских разработок и производства.

Длинный перечень подобных проблем возникает не только в процессе реализации проекта МЦСР. Высшая школа, за редкими исключениями, никогда прежде не занималась инновациями, если под ними понимать результат творческой деятельности, получивший воплощение в виде новой или усовершенствованной продукции или технологии [4]. На это обстоятельство обращает внимание чиновников от науки множество реально двигающих науку и генерирующих инновации ученых. В частности, директор Всероссийского института авиационных материалов (ВИАМ) академик РАН Е.Н. Каблов отмечает: «Главная задача вузов - это образование. Сейчас им выделили большие деньги на приобретение оборудования, но задачи, для решения которых оно приобретается, не обозначены. В результате пока мы видим только бессистемные траты и потерю средств, в которых так нуждаются уже реально работающие научные центры» [4].

Однако хотя в высказывании академика РАН Е.Н. Каблова большая доля истины, авторы не являются сторонниками того, чтобы начатые процессы формирования инновационной среды на базе высшей школы повернуть вспять. В конечном итоге, кадровая скамейка является короткой не только в НИУ, и задачей текущего момента является правильное использование созданных государством возможностей. Это требует создания соответствующей уровню заявленных амбиций системы управления инновационными процессами - инновационного менеджмента. При этом речь, безусловно, идет о прикладных исследованиях и их практической реализации, в частности, в проектах, реализуемых НИУ-ПГТУ.

Для решения этой задачи в НИУ-ПГТУ под научным руководством академика РАН А. И. Татаркина организован НИЦ УН - научно-исследовательский центр управления инновациями (структура управления НИЦ УН представлена на рис. 3).

Задачей НИЦ является разработка принципов, методов и инструментов управления процессами создания продуктово-технологических и управленческих инноваций в научно-исследовательском университете, инновационных 


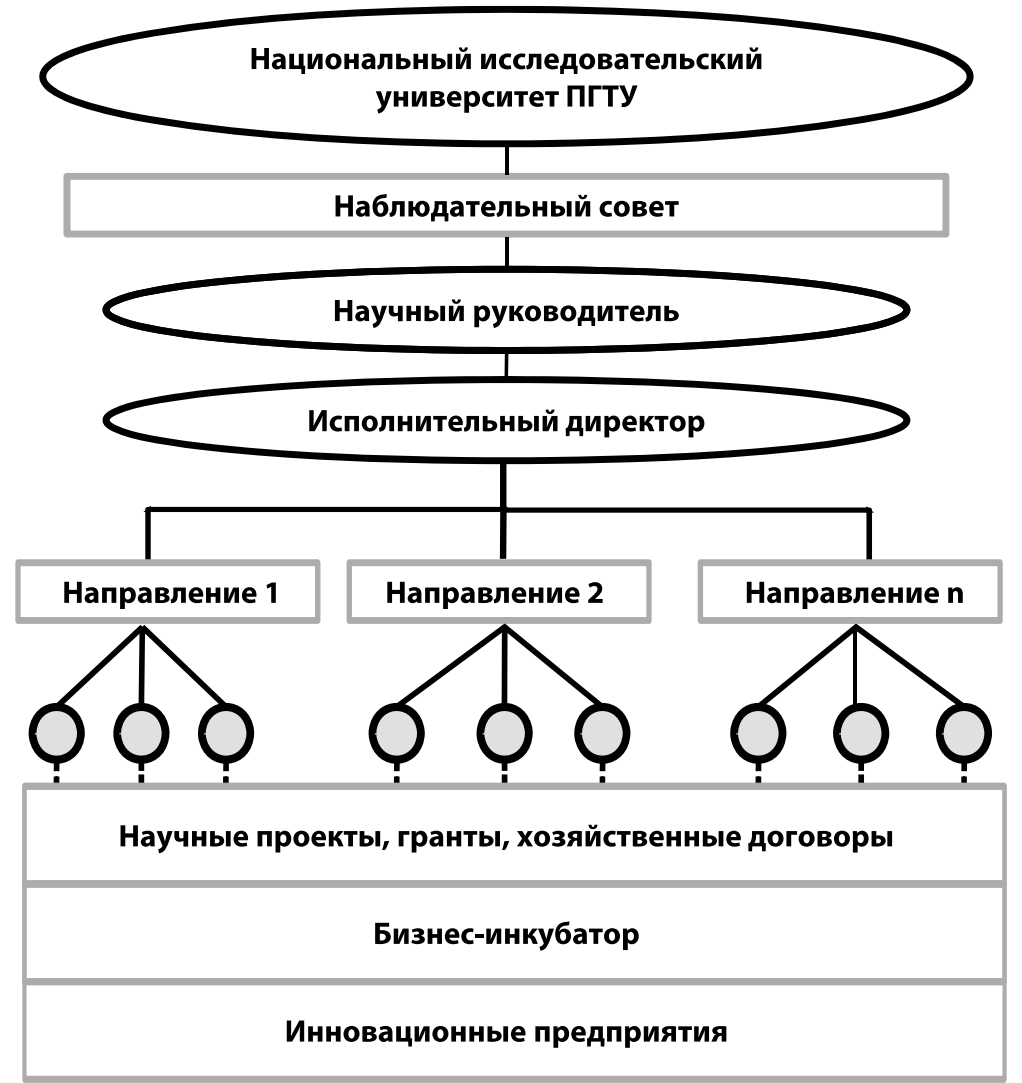

Рис. 3. Структура Научно-исследовательского чентра управления инновациями (НИЦ УН) кластерах и инновационных компаниях на территории региона. В качестве основных фундаментальноприкладных проблем определены следующие:

- методология и технология генерации нового знания (интеллектуальные сети, когнитивные технологии);

- методология и процесс формирования инновационно-предпринимательских компетенций сотрудников и потенциала персонала организаций;

- методология и технология саморазвивающихся инновационных систем (инновация как внутренняя необходимость; социальное предпринимательство: слияние личного и бизнеса; технологическое брокерство, социальные сети, живые корпорации; цепочки создания инновационной ценности; организационноповеденческие механизмы разделения труда в интеллектуальной сфере; саморазвивающиеся организации);

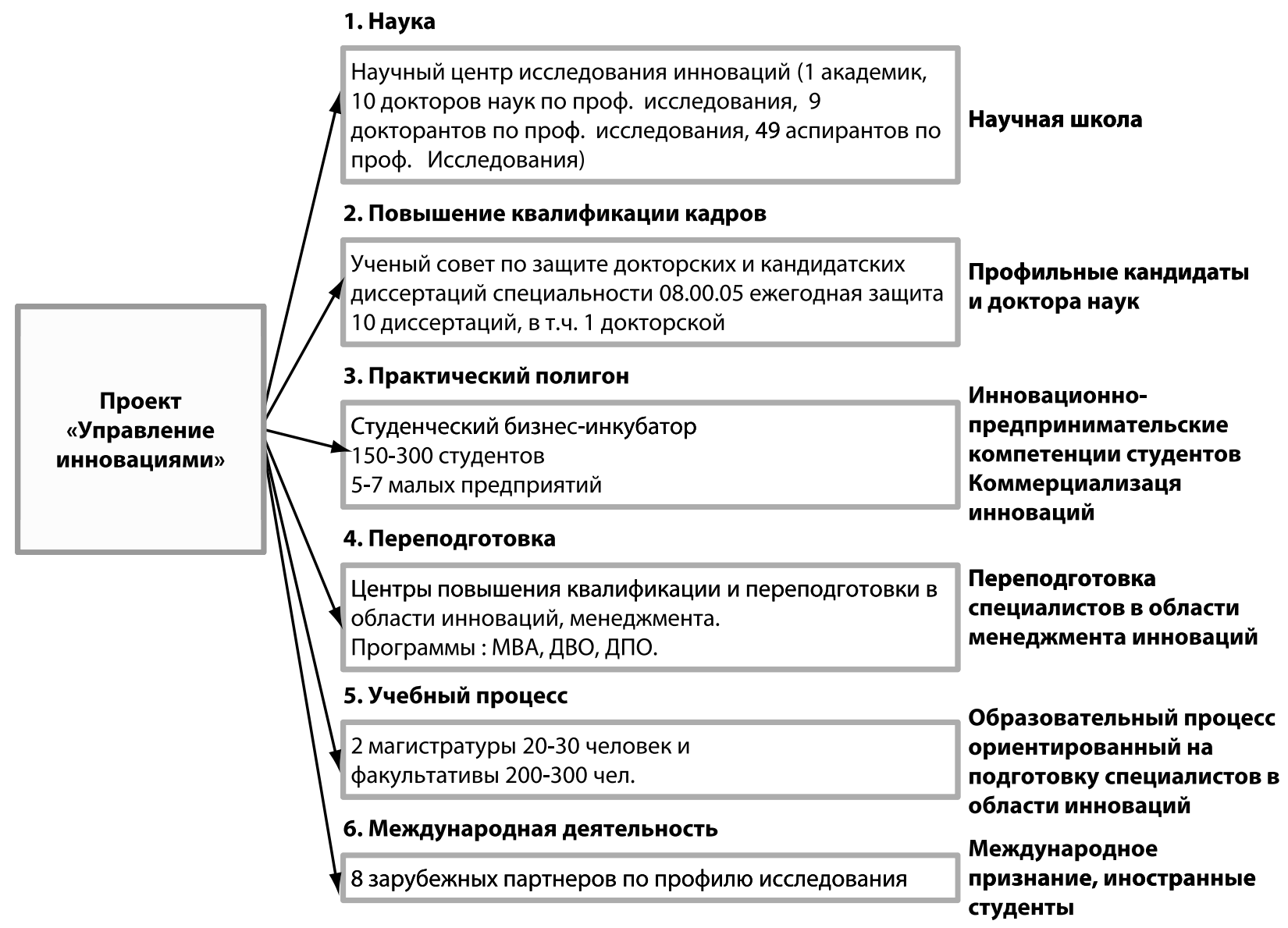

Рис. 4. Структура и направления проекта «Управление инновациями» 
- методология и механизмы формирования и мониторинга инноваций потребительских ценностей (поведенческое потребление, сегментация как способ увеличения потребительских ценностей, механизмы привлечения инноваций и инициатив от клиентов - социальные сети);

- теория и методы измерения инновационных изменений, измерение трансформаций, диагностика ограничений).

Стратегической задачей развития НИЦ УН является организационное оформление деятельности центра в ПНР с названием «Менеджмент инноваций» в соотвествии с утвержденной приказом Министерства образования и науки РФ от 12 ноября 2009 г. №591 «Программы развития ГОУ ВПО ПГТУ на 2009-2018 гг.» [5]. На основе плана исследований в разрезе обозначенных выше фундаментально-прикладных проблем исходя из требований, предъявляемых к ПНР, разработаны основные показатели развития проекта « Менеджмент инноваций» (рис. 4).

Резюмируя вышеизложенное, следует отметить, что реально инновационное развитие вузовской науки в форме инновационных кластеров на базе НИУ должно базироваться на интеграции с инновационными компаниями. Критериями отбора проектов должна быть их значимость и конкурентоспособность на международном уровне. Инструментом эффективного инновационного развития призван стать менеджмент инноваций как неотъемлемая составная часть системы.

\section{Список источников}

1. Гуриев С., Плеханов А., Сонин К. Экономический механизм сырьевой модели развития // Вопросы экономики. 2010. №3. С. 4-23.

2. Сурин А. В., Молчанова А. П. Инновационный менеджмент: учебник. М.: Инфра-М, 2008. 368 с.

3. Максимов А. Д., Максимов Т. А. Антикризисная стратегия машиностроительного предприятия // Экономика региона. 2009. №3. С. 70-79.

4. Механик А. Почему лопатки разрушаются изнутри // Эксперт. 2010. №14. С. 50-58.

5. Программа развития государственного образовательного учреждения высшего профессионального образования «Пермский государственный технический университет» на 2009-2018 гг. (Утверждена приказом Министерства образования и науки РФ от 12.11.2009 г. №592). [Электронный реcypc]. URL: http://pstu.ru/news/2009/11/16/490.

\section{УДК 338.24:001.895}

ключевые слова: инновационные предприятия, исследовательский университет, интеграция 